\title{
Research Methods: Issues and Research Direction
}

\author{
Linus Osuagwu ${ }^{1}$ \\ ${ }^{1}$ School of Business \& Entrepreneurship, American University of Nigeria, Lamido Zubairu Way, Yola, Adamawa \\ State, Nigeria \\ Correspondence: Linus Osuagwu, School of Business \& Entrepreneurship, American University of Nigeria, Lamido \\ Zubairu Way, Yola, Adamawa State, Nigeria. Tel: 234-80-3303-6440. E-mail: osuagwulinus@gmail.com
}

Received: September 15, 2020

Accepted: September 28, 2020 Online Published: September 30, 2020

doi:10.5430/bmr.v9n3p46

URL: https://doi.org/10.5430/bmr.v9n3p46

\begin{abstract}
This paper proposes a research plan to investigate the research methods issues (i.e. research design, sampling methods, data collection methods, data analysis techniques, measurement scales, and reliability/validity tests, among others) used in business students' thesis/dissertation works in institutions of higher learning. Specifically, the proposed research aims to help in understanding the dominant research methods used by thesis/dissertation research students in the field of business management in institutions of higher learning, shed light on possible relevant research methodology issues in business management education and proffer managerial and theoretical recommendations that will assist research methodology in business disciplines in institutions of higher learning. Among other things, the proposed investigation is expected to help in assessing the quality and relevance of business research works in higher institutions; assist in repositioning business education curricula to align with academic, regulatory and industry expectations; improve the quality and relevance of research works undertaken in business schools in institutions of higher learning; and stimulate research in cognate areas.
\end{abstract}

Keywords: Research methods, business schools, students, research framework

\section{Introduction}

The need for advanced and specialized forms of knowledge motivated the establishment of different kinds of higher institutions in many countries. Research is one of the main foci of any institution of higher learning, with the others being teaching and community service.

Generally, research is about knowledge creation, which comprises development of theory and finding of facts via systematic investigation (Henneberg \& O'Shaughnessy, 2007). Research entails systematic search for new knowledge via understanding and application of appropriate methods in order to provide answers and draw conclusions (Christiani, 2016), and research may be undertaken when gaps exist between organizational knowledge and empirical methods (McNichols, 2000). According to Sa and Serpa (2020), any scientific research comprises two aspects: the Process and the Product. The Process deals with the methods used to address the problem of research interest, while the Product deals with results emanating from the Process. Generally, research methods are the foundation for the generation of knowledge in any discipline or domain, including business management, and are influenced by research issues and paradigm or philosophy of interest to the researcher (Pinsonneault \& Kraemer, 1993; Dube \& Pare, 2003).

Research is a major activity of any higher institution. As a result, it is given high priority by students, Lecturers, institutional management, regulatory agencies and funding agencies, among others. For example, lecturers are promoted on the basis of their research quality and quantity. Also, students are awarded degrees on the basis of completing quality research works. Therefore, the quality of lecturers' and students' research works is of serious concerns to management, regulators, funding agencies and owners of institutions of higher learning. This is because such research works are expected to have relevance for learning, teaching and solution of national and societal problems. However, the relevance of such research works depends on the research methods employed, in addition to the significance of the research works in providing theoretical and practical solutions to societal challenges. Research methods and methodologies are used to make correct inferences and to answer relevant research questions (Wahyuni, 2012).

As business education and its research continue to advance and mature in many institutions of higher learning, it is important for researchers to assess the methods that are employed in investigating issues of business and managerial 
relevance. Such assessment avails stakeholders insights regarding the rigour and appropriateness of the research methods used, in addition to relevance associated with the research results (Pfeffer, 1993; Scandura \& Williams, 2000, Bouckenooghe et al., 2007). Researchers make such research methods decisions with regard to research design used, data collection methods employed, measurement scales used, sampling approaches employed, methods for testing reliability and validity, data analysis methods used, and practical and theoretical forms of significance associated with the research (Stone-Romero, 2002). Generally, it may be argued that research in business schools in institutions of higher learning could benefit from more triangulation in research strategies, more advanced analytical techniques and methodologies, and more longitudinal research resulting in higher reliability and validity levels (Bouckenooghe et al., 2007).

Business students in institutions of higher learning are usually exposed to many forms of research methods trainings which include focus group discussions, case studies, surveys, projective techniques, and statistical methods, among others (Fedotova, 2013; Vorobyeva \& Ermakov, 2015). Therefore, it is useful for business students in institutions of higher learning to have understanding regarding the degree to which the research methods employed in their relevant studies give them latitude to make valid and reasonable conclusions and inferences pertaining to cognate research findings in the field of business management/administration. According to Scandura and Williams (2000), the further development of any discipline (such as business management) is a function of the appropriateness and rigour of the chosen research methods. With regard to marketing research, Umer and Razi (2018) have, via systematic literature review, explored the major research methods employed in service marketing studies, concluding that there have been preferences for survey methods, factor analysis, structural equation modeling (SEM), ANOVA (Analysis of variance), and tests of reliability and validity of research measures. Generally, research methodology development in any discipline should be a function of knowledge of the relevant concepts, approaches and phenomena to be investigated (Zaltman, 1997). Researchers need measures for the evaluation of their research works (Muller, 2013), and evaluation of the value of any research effort entails using indices that are relatively simple and understandable, free from all forms of bias (Petersen, 2019), in addition to using appropriate research methods. However, some researchers use certain methods of research based on their knowledge of the methods (Constantin, 2012). The chosen method may or may not be appropriate for the research in question.

Research is one of the salient activities of an institution of higher learning (Soutar et al, 2015), and academics in institutions of higher learning, including students, are required in their careers to engage in scholarly research activities (Abbott, 2019). Research methodology courses for students in institutions of higher learning provide students with relevant knowledge and skills needed to conduct research (Balloo et al., 2016). In addition, via their research activities and publications, academics in institutions of higher learning (including students) publish in scholarly outlets ((Kwiek, 2020). Also, students' understanding of research methods helps them in enhancing their professional career profile, developing abilities in addressing complex organizational issues, analyzing associated research data, and drawing relevant conclusions and insightful recommendations (Alexandrov \& Alexandrov, 2015). However, professors are different regarding the research methods they teach and expose their students to, including the methods used by students in their theses/dissertation works (Mitchell \& Jolley, 2010). In addition, Ijaz (2019) posits that some students' research interests tend to wane as their academic training progresses. This paper isolates some major business research methods issues of relevance for business management students' research theses/dissertations, and proposes a research direction. Specifically, the paper discusses salient dimensions of research methods (such as research design, data collection methods, measurement, sampling, data analysis, and reliability and validity tests) and proposes a research direction for business students in their theses/dissertation works.

\section{Dimensions of Research Methods}

Research, generally, can be conceptualized as the systematic, objective, (sometimes subjective) conceptualization of problems and the consequent collection, analysis, interpretation and reporting of data and information in order to clarify the identified problems and/or solve them. It is the process associated with arriving at problem solutions via objective, planned and systematic data collection, analysis and interpretation (Osuagwu, 2008). Many research methods and techniques can be used for basic and applied types of research. However, the research methods/techniques used should be a function of the resources available, the research problem being investigated, the research environment, the relevant research variables in focus, and the audience for the research report, among others. Research objective, research process (method) and research results (product) are some of the major pillars of any research work. Scholarly publications (products) represent an important aspect of the research community (Schwab-McCoy, 2019).

Research is, also, a scientific, reliable, and valid way of acquiring knowledge. It is thrusted towards knowing the relationships between and among variables of the phenomena being studied. According to Osuala (1990), research is 
the most important tool for the advancement of knowledge and promotion of national/organizational growth and progress, in addition to enabling humans to live happily in the society and relate with their relevant environments. There are three major research approaches, which include quantitative, qualitative and triangulation of quantitative and qualitative methods, also known as mixed methods of research (Williams, 2007).

Conceptually, research methods are different from research methodologies. A business research methodology, for example, is a model within a specific research paradigm (i.e., positivist, relativist, or mixed methods), while a research method deals with a particular research procedure, technique or tool (including a combination of these) relevant for a research work. Therefore, research method is practical research application (such as use of interviews for data collection), while methodology is theoretical foundation or philosophy guiding a specific research method used (Wahyuni, 2012).

Research methods, generally, include designing studies, collecting data, analyzing collected data, testing for relevant relationships/differences between/among variables, making sense out of research findings and reporting the findings to the relevant audience in the appropriate format. Daft (1983) submits that using data to describe and explain how organizations/institutions function is the "why" of research. Alias et al. (2013) have investigated, via content analysis method of data collection, research methods trends of journals with regard topics investigated, research contexts or settings, sampling methods used, research designs employed, and data analysis methods utilized, among others. In a research work undertaken by Akdemir et al. (2015) regarding curriculum development in education, results indicated that document analysis was the preferred data collection technique; the preferred sampling method was purposeful sampling, while qualitative research method was preferred to quantitative research approach. Erdogan et al. (2012) isolated, via content analysis approach, some concerns in the research methods used in some studies with regard to their research designs, samples used, data collection instruments employed, reliability and validity tests conducted, and data analysis methods used.

Business organizations are complex and multi-dimensional. Therefore, many research methods can be employed by organizational managers, or those studying organizational tendencies, including academics, researchers and students. Generally, the research methods that can be used to study organizational tendencies relate to such issues as research design, sampling methods, data collection methods, data analysis methods, measurement scales, reliability and validity tests, and data analysis methods, among others. Improvement in research methods, generally, is accomplished via issues relating to new comprehension and application of the scientific approach, among other cognate issues (Zaltman, 1997), and every research method is an approach for attending to a specified research problem (Kubas \& Stofkova, 2017). Therefore, effective research is a function of proper comprehension and definition of the problem to be investigated (Eden \& Ackermann, 2018), in addition to the utilization of appropriate, efficient and effective methods of investigation. Some basic research methods issues include research design, data collection methods, measurement methods, sampling methods, reliability and validity tests, and data analysis, among others (Kubas \& Stefkova, 2017). These research methods issues are further discussed in this paper.

\subsection{Research Design}

Research design is the program that guides the researcher in the process of collecting, analyzing and interpreting data and information. It defines the domain of generalizability; that is, whether the obtained research interpretation can be generalized to a larger population or to different situations. Research design has four components namely comparison, manipulation, control and generalizability. The main purpose of research design is to provide answers to research questions and to control variance. The strengths of a good research design are evident in research works utilizing randomness (Angrist \& Pischke, 2010). According to Rahi (2017), quantitative and qualitative research methods are the most dominant research design approaches.

Research design is the plan that guides a researcher in the process of collecting, analyzing and interpreting data and information for clarifying and solving organizational/national problems. It attempts to connect research methodologies to a set of research methods for the purpose of drawing reasonable inferences (Wahyuni, 2012). According to Kerlinger (1983), research design is the plan, structure and strategy for a research work which is conceived in order to get data and information for relevant research problems and to control variance. It provides basic guidelines for conducting research and may be seen as a series of interrelated decisions that serves as a master plan for an investigation (Luck \& Rubin, 1989). Generally, research designs address research issues pertaining to data collection methods (e.g. survey, field or experimentation), measurement scales used, sampling techniques used, data analysis techniques utilized and methods used for reliability and validity tests, among others. There is no generally accepted research design. Research methodology in the social and human sciences has continued to evolve, with mixed methods research design approach (which combines the strengths of quantitative and qualitative research approaches) being the latest phase in the 
evolution of research methodology (Creswell, 2009).Therefore, researchers utilize a combination/triangulation of research designs in order not to generate research findings that have questionable theoretical and practical implications (Joslin \& Muller, 2016). Generally, triangulation in research relates to data, researcher, methodology, theory, and philosophy/paradigm (Joslin \& Muller, 2016), and research objectives and the associated research questions are the foundations for a research design (Wahyuni, 2012; Yin, 2012). Major research designs used in business research are exploratory, descriptive and causal research designs.

\subsection{Data Collection Methods}

Data can be defined as raw or unprocessed facts. It can also be defined as facts usually collected as the result of experience, observation or experiment. Data may consist of numbers, words, or images, or as measurements or observations of a set of variables. Data are often viewed as a lowest level of abstraction from which information and knowledge are derived. Data collection methods can be combined to collect primary and secondary forms of data (Patton, 2002; Wahyuni, 2012).

There are many data collection methods in research, each having its strengths and weaknesses (McGrath, 1982). The choice of data collection methods to be used in business research is a major research issue. A researcher (such as a student) must have thorough and adequate knowledge of the relevant data collection methods to be used. These methods include surveys, interviews, focus groups, experimentation, observations, content analysis, meta-analysis, case study, and archives, among others. For example, experiments are a widely used research method in marketing, but business researchers, generally, rely on surveys, observations, or interviews to collect data. Data collection via survey method is efficient and gives quick turnaround (Frippiat \& Marquis, 2010), although with decrease in survey response rates over the years (Schmeets, 2010).

Surveys, generally, have been associated with some difficulty in addition to cost inefficiency (Nesbary, 1999). However, Majhi et al (2016), in an empirical research work via content analysis method of data collection, reported that survey research and descriptive data analysis were the most used research methods. Also, online survey methods possess some benefits relating to cost efficiency, high response rate, better quality of response rate, better quality of responses, time efficiency, and reduced interviewer bias, among others (Lee, 2010). Experimental methods of data collection, on the other hand, strive for precision by controlling variables in the research environment (Davis et al., 2012). Most of the empirical research works in the management and behavioural disciplines use the quantitative method of research, and data collection is via questionnaire (Baruch and Holtom, 2008). Research methods used in the social and behavioural science disciplines, including data collection methods, should be contextualized (Flyvbjerg, 2001).

\subsection{Measurement in Research}

Measurement in research is conceptualized as the assignment of numbers or quantities to variables or things. It is the peculiarities of the objects that are being measured (Kinnear \& Taylor, 1983). Generally, the aim of measurement in research is to provide an empirical estimation of relevant research constructs (Malhotra et al., 2012), and measurement scales to be used for research across countries are required to be relevantly generalizable (Sharma \& Weathers, 2003). Methodological concerns associated with research measurement scales have been adequately reviewed by Ladhari (2010). Effective measurement in research is possible when the relationships existing among the objects or events in the empirical system directly correspond to the rules of the number system. In a business research measurement scale, positively and negatively worded items can be used in the same measurement scale, although the advantages and disadvantages associated with this measurement approach should be noted (Salazar, 2015). The most popular measurement format for collecting quantitative data is via rating scales, which include Likert-type scales (Lee \& Soutar, 2010; Pearse, 2011).

Some of the measurements scales used in business research are nominal scale, ordinal scale, interval scale and ratio scale. Each of these scales has its permissible statistics (Luck \& Rubin, 1989). Also, there is sample size requirement in relation to the use of certain data analytic techniques. In exploratory factor analysis (EFA), for example, the recommended minimum sample size is 100 to 500 respondents, and the recommended minimum ratio of number of sample respondents to number of items in the measurement scale ranges from 3:1 to 10:1 (MacKenzie et al., 2011). Reliability and validity are the two most important features of a measurement method (Bajpai \& Bajpai, 2014). According to Croasmum and Ostrom (2011), it is important to determine Cronbach's alpha reliability coefficient when Likert-type measurement scales are used in research works. In addition, single-item and multi-item measurement scales can be used in business research, with multi-item measurement scale being preferred to single-item measurement scales (Diamantopoulos, 2012). 


\subsection{Sampling in Research}

Sampling is the process of drawing a subset or sample from a population. A sample is a finite part of a statistical population whose properties are studied to gain information about the whole/population. When dealing with people, it can be defined as a set of respondents (people) selected from a larger population for the purpose of a survey/research. Inadequate sample size has negative impact on the accuracy of research results (Barlett et al., 2001). Sampling can be classified into probability and nonprobability types (Rahi, 2017). In probability sampling approach, the chance or likelihood of a subject or an element being included in the sample is known or the chance of someone being selected is known. In nonprobability sampling approach, the reverse is the case, and the subject or element being included in the sample is not known. Use of nonprobability sampling approach limits generalization from research findings unlike probability sampling methods (Onwueguzie \& Johnson, 2006; Etikan \& Bala, 2017). Non probability sampling methods include quota sampling, accidental/convenience sampling, judgmental or purposive sampling, expert sampling, and snowball sampling, among others. Probability sampling methods, which have been the dominant sampling methods over the years (Sarstedt et al, 2017), include systematic sampling, stratified sampling, cluster sampling, multistage sampling, and area sampling, among others. Probability sampling methods are preferred mostly by statistical organizations, while nonprobability sampling approaches are preferred mostly by business organizations, marketers and researchers (Etikan \& Bala, 2017). Generally, nonprobability sampling methods have the advantages of ease of use, ease of securing cooperation from research respondents, and cost efficiency, but have the disadvantages of lack of representativeness and generalizability of research results from sample to the population which can limit research replication (Levy \& Lemeshow, 2013; Lehmann \& Bengart, 2016; Sarstedt et al, 2017).

\subsection{Reliability and Validity in Research}

Generally, the criteria used in determining the quality of any research include reliability, validity and generalizability (Ali \& Yusof, 2011). Reliability of a research measure/instrument is an indication of whether it measures anything at all. It is an index of the internal consistency of a research instrument (Kayes, 2005). The notion of consistency has been developed by researchers to estimate reliability in research measures, and helps researchers have confidence in their research measures. A business research instrument (for example, questionnaire) with a reliability coefficient of 0.7 means that $30 \%$ of its variance is irrelevant or is associated with error. A research instrument's reliability can be assessed via Cronbach' alpha (Cronbach, 1951) method, in addition to exploratory and confirmatory factor analysis approaches (Walls et al., 2011).

Validity can be defined as the degree to which a test measures what it is supposed to measure. Validity, generally, is a measure of how well a research-measuring instrument or scale measures what is intended to measure (Bajpai \& Bajpai, 2014). A research instrument is valid if it measures what is intended to measure accurately. Validity deals with accuracy while reliability deals with replicability. Using valid research instruments or scales is an important condition for research in business and science, and reliability is a necessary condition for validity of a research instrument or scale (Knight, 1997). According to Peter (1979), the advancement of business is a function of developing and designing reliable and valid research instruments or scales, and reliability and validity are the necessary conditions for drawing research inferences and conclusions (Sarstedt et al., 2017).

Also, reliability and validity tests are important in research because they enhance transparency and decrease bias from researchers (Singh, 2014), in addition to helping in the determination of measurement errors and relevant relationships between and among research variables (Mohajan, 2017). The rigour and strength of any research work are a function of the reliability and validity tests associated with the research (Morris \& Burkett, 2011). Business students, professors, and programme assessors evaluate the quality of students' theses/dissertations and cognate research works on the bases, among others, of the quality criteria of reliability, validity and generalizability (Smallbone \& Quinton, 2004). Types of validity tests generally used in empirical social research, including business research, include content validity, construct validity, internal validity, external validity and reliability (Yin, 2003). Content validity, for example, deals with the power of a research measuring instrument's items to measure the intended concept (Astuti et al, 2018). Construct validity deals with how well research results align with the associated theory from where the research measurement or scale is derived, and is assessed via convergent and discriminant validity (Bajpai \& Bajpai, 2014). However, it should be noted that validity in research is associated with certain threats (Onwueguzie \& Johnson, 2006).

\subsection{Data Analysis in Research}

Data analysis in business research is concerned with the categorizing, ordering, manipulating and summarizing of data in order to get relevant answers to research questions. According to Book and Epstein (1982), data analysis is concerned with searching and finding out what information that can be isolated from a set of research data using appropriate analytical tools. It is concerned with the making of reasonable inferences from raw data (Wahyuni, 2012). 
The aim of data analysis in business research is for the reduction of data to reasonable, discernible and interpretable forms so as to test and understand relations between/among research variables. It helps to reveal relevant information from research data using multivariate methods (Rajalahti \& Kvalheim, 2011), although outlier data can adversely affect data analysis, thereby leading to faulty research conclusions (Moller et al., 2005). The use of multiple methods to conduct data analysis in research is referred to as triangulation of data analysis methods (Patton, 2002), and there are many data analytic tools, techniques, packages and software that can be used by researchers for quantitative and qualitative data analyses. For instance, Singh and Modi (2019) studied major research trends using information modeling techniques. Also, multiple regression analysis is a statistical tool that helps in organizing research thoughts and development of relevant theories (Woodside, 2013). The appropriateness of the data analysis methods used in a specific research helps in determining the statistical conclusion validity associated with the research in question. The data analysis step in research is connected to other steps in the research process. For instance, sophisticated data analysis method cannot solve research defects associated with poorly designed sampling methods (Sarstedt et al., 2017). Also, data analysis is affected by missing data (Livacic-Rojas et al., 2020).

\section{Conclusion and Proposed Research Direction}

Research methods used in business and allied disciplines include the quantitative, qualitative and triangulation of quantitative and qualitative methods, also known as mixed methods forms of research. Research works in business disciplines, generally, have theoretical and practical forms of relevance, and this relevance is substantially a function of the research methods utilized. It can be concluded, therefore, that there are many types of business research methods with issues relating to research design, data collection methods, sampling approaches, measurement methods, data analysis methods, and reliability and validity test issues, among others. The extent to which these issues are addressed in research works will go a long way in determining the quality and relevance of such studies. In addition, periodic assessment of business research methods used by scholars, researchers and students will assist in improving the rigour and relevance of research works.

Based on relevant conceptualizations of research methods issues presented in this paper, a research direction is proposed. The proposed research should seek to investigate the areas in which business students in institutions of higher learning have placed research emphases in terms of topics/problems investigated, research design used, sampling method employed, measurement methods used, data analysis methods used, validity and reliability tests conducted, practical managerial recommendations given, theoretical/academic recommendations made, and areas suggested for further studies. These are the general issues that seek to determine the quality of any research endeavour in the academia. The content analysis method of research, among other relevant research methods, can be used for the proposed research. The content analysis method of research has been conceptualized as a qualitative research approach which is utilized in making replicable and valid research inferences from research data to their relevant contextual settings (Kippendorff, 1980), in addition to studying changes in trends, contents and methods (Loy, 1979). The proposed research direction is likely to assist in evaluating the quality of research works undertaken by business management students in institutions of higher learning, highlight observed deficiencies in students' research theses/dissertations, and help professors and institutional assessors and accreditors to ensure that relevant research methods issues are taught, practised and assessed (Smallbone \& Quinton, 2004).

\section{References}

Abbott, A. (2019). Career stage and publication in American academic. Sociologia, 90, 9-30. https://doi.org/10.7458/SPP20199014297.

Akdemir, E., Karamese, E. N., \& Arslan, A. (2015). Descriptive analysis of researches on curriculum development in $\begin{array}{lllll}\text { education. } & \text { Procedia-Social and Behavioral }\end{array}$ https://doi.org/10.1016/j.sbspro.2015.01.1062.

Alexandrov, N., \& Alexandrov, V. (2015). Computational science research methods for science education at PG level. Procedia Computer Science, 51, 1685-1693. https://doi.org/10.1016/j.procs.2015.05.305.

Ali, A. M., \& Yusof, H. (2011). Quality in qualitative studies: The case of validity, reliability and generalizability. Issues in Social and Environmental Accounting, 5(1/2), 25-64.

Alias, N., Sabdan, M. S., Aziz, K. A., Mohammed, M., Hamidon, I. S., \& Jomhari, N. (2013). Research trends and issues in the studies of Twitter: A content analysis of publications in selected journals (2007-2012). Procedia-Social and Behavioral Sciences, 103, 773-780. https://doi.org/10.1016/j.sbspro.2013.10.398. 
Angrist, J. D., \& Pischke, J. (2010). The credibility revolution in empirical economics: How better research design is taking the con out of econometrics. Journal of Economic Perspectives, 24(2), 3-30. https://doi.org/10.1257/jep.24.2.3.

Astuti, A. D., Nurjannah, I., \& Mulyani, S. (2018). Validity and reliability of instrument to measure clinical indicator of nursing diagnosis: Fatigue on patient undertaking haemodialysis. Belitung Nursing Journal, 4(3), 350-355. https://doi.org/10.33546/bnj.424.

Bajpai, S., \& Bajpai, R. (2014). Goodness of measurement: Reliability and validity. International Journal of Medical Science and Public Health, 3(2), 112-115. https://doi.org/10.5455/ijmsph.2013.191120133.

Balloo, K., Pauli, R., \& Worrell, M. (2016). Individual differences in psychology undergraduates' development of research methods knowledge and skills. Procedia-Social and Behavioral Sciences, 217, 790-800. https://doi.org/10.1016/j.sbspro.2016.02.147.

Barlett, J. E., Kotrlik, J. W., \& Higgins, C. C. (2001). Organizational research: Determining appropriate sample size in survey research. Information Technologies, Learning, and Performance Journal, 19(1), 43-50.

Baruch, Y. \& Holtom, B.C. (2008). Survey response rate levels in organizational research. Human Relations, 61(8), 1139-1160.

Book, S. A., \& Epstein, M. J. (1982). Statistical Analysis. New Jersey: Scot Freeman \& Co.

Bouckenooghe, D., De Clercq, D., Willem, A., \& Buelens, M. (2007). An assessment of validity in entrepreneurship research. Journal of Entrepreneurship, 16(2), 147-172.

Christiani, T. A. (2016). Normative and empirical research methods: Their usefulness and relevance in the study of law as an object. Procedia-Social and Behavioral Sciences, 219, 201-207. https://doi.org/10.1016/j.sbspro.2016.05.006

Constantin, C. (2012). A comparison between multivariate and bivariate analysis used in marketing research. Bulletin of the Transylvania University of Brasov, Series V, 5(54), 1-8.

Creswell, J. W. (2009). Research Design: Qualitative, quantitative, and mixed methods approaches (3rd ed.). Los Angeles: Sage.

Croasmum, J. T., \& Ostrom, L. (2011). Using Likert-type scales in the social sciences. Journal of Adult Education, 40(1), 19-22.

Cronbach, L. J. (1951). Coefficient alpha and the internal structure of tests. Psychometrika, 16, 297-334. https://doi.org/10.1007/bf02310555.

Daft, L. R. (1983). Learning the craft of organizational research. Academy of Management Review, 8(4), 539-546.

Davis, D. F., Golicic, S. L., Boerstler, C. N., Choi, S., \& Oh, H. (2012). Does marketing research suffer from methods myopia? Journal of Business research, 1-3. https://doi.org/10.106/j.busres.2012.02.020.

Diamantopoulos, A., Sarstedt, M., Fuchs, C., Wilczynski, P., \& Kaiser, S. (2012). Guidelines for choosing between multi-item and single-item scales for construct measurement: A predictive validity perspective. Journal of the Academy of Marketing Science, 40, 434-449. https://doi.org/10.1007/s11747-011-0300-3.

Dube, L., \& Pare, G. (2003). Rigor in information systems positivist case research: Current practices, trends and recommendations. MIS Quarterly, 27(4), 597-635.

Eden, C., \& Ackermann, F. (2018). Theory into practice, practice to theory: Action research in method development. European Journal of Operational Research, 271, 1145-1155. https://doi.org/10.1016/j.ejor.2018.05.061.

Erdogan, M., Kaplan, H., Kayir, C. G., Asik, U. O., \& Akbunar, S. (2012). Common method-related problems in selected research studies on educational sciences in Turkey. Procedia-Social and Behavioral Sciences, 46, 320-3234. https://doi.org/10.1016/j.sbspro.2012.06.042.

Etikan, I., \& Bala, K. (2017). Sampling and sampling methods. Biometrics \& Biostatistics International Journal, 5(6), 1-3. https://doi.org/10.15406/bbij.2017.05.0049.

Fedotova, O. (2013). Radicalism and terrorism problems in scientific discourse of Russian social sciences. Procedia-Social and Behavioral Sciences, 92, 334-343.

Flyvbjerg, B. (2001). Making social science matter. Cambridge, England: Cambridge University Press.

Frippiat, D., \& Marquis, N. (2010). Web surveys in the social sciences: An overview. Population, 65(2), 285-311. 
Henneberg, S. C., \& O'Shaughnessy, N. J. (2007). Theory and concept development in political marketing. Journal of Political Marketing, 6 (2\&3), 5-31. DOI: 10.1300/J199v06n02_02.

Ijaz, N. (2019). Research-related attitudes among Chinese medicine students at a Canadian college: A mixed-methods study. Integrative Medicine Research, 8, 264-270. https://doi.org/10.106/j.imr.2019.10.001.

Joslin, R., \& Muller, R. (2016). Identifying interesting project phenomena using philosophical and methodological triangulation. International Journal of Project Management, 1-14. https://doi.org/10.106/j.ijproman.2016.05.005.

Kayes, D. C. (2005). Internal validity and reliability of Kolb's learning style inventory version 3 (1999). Journal of Business and Psychology, 20(2), 249-257. https://doi.org/10.1007/s10869-005-8262-4.

Kerlinger, F. N. (1983). Foundations of behavioral research. New Delhi: Surjeet Publications.

Kinnear, T. C., \& Taylor, J. R. (1983). Marketing research. New Delhi: Prentice Hall of India Private Ltd., 7th Ed.

Knight, G. A. (1997). Reliability and validity of a scale to measure firm entrepreneurial orientation. Journal of Business Venturing, 12, 213-225.

Krippendorff, K. (1980). Content analysis: An introduction to its methodology. London: Sage.

Kubas, J., \& Stofkova, Z. (2017). Application of some research methods to determine the level of safety in municipalities. Procedia-Social and Behavioral Sciences, 237, 242-248. https://doi.org/10.1016/j.sbspro.2017.02.070.

Kwiek, M. (2020). The prestige economy of higher education journals: A quantitative approach. Higher Education, 13, 1-27. https://doi.org/10.1007/s10734-020-00553-y

Ladhari, R. (2010). Developing e-service quality scales: A literature review. Journal of Retailing and Consumer Services, 17, 464-477. https://doi.org/10.1016/j.jretcanser.2010.06.003.

Lee, B. (2010). Exploring a new research method in diversity research. Procedia- Social and Behavioral Sciences, 7C, 494-503. https://doi.org/10.1016/j.sbspro.2010.10.1067.

Lee, J. A., \& Soutar, G. (2010). Is Schwartz's value survey an interval scale, and does it matter? Journal of Cross-Cultural Psychology, 41(1), 76-86.

Lehmann, S., \& Bengart, P. (2016). Replications hardly possible: Reporting practice in top-tier marketing journals. Journal of Modelling in Management, 11(2), 427-445.

Levy, P. S., \& Lemeshow, S. (Eds.) (2013). Sampling of populations: Methods and applications (5th Ed.). Hoboken, NJ: John Wiley and Sons.

Livacic-Rojas, P., Fernandez, P., Vallejo, G., Tuero-Herrero, E., \& Ordonez, F. (2020). Sensitivity of five information criteria to discriminate covariance structures with missing data in repeated measures design. Psicothema, 32(3), 399-409. https://doi.org/10.7334/psicothema2020.63.

Loy, P. (1979). Content analysis of journal articles as a technique for historical research. Journal of the History of Sociology, 1(2), 93-101.

Luck, D. J., \& Rubin, R. S. (1989). Marketing research. New Delhi: Prentice Hall of India Private Ltd, 7th Ed.

MacKenzie, S. B., Podsakoff, P. M., \& Podsakoff, N. P. (2011). Construct measurement and validation procedures in MIS and behavioral research: Integrating new and existing techniques. MIS Quarterly, 35(2), 293-334.

Majhi, S., Jal, C., \& Maharana, B. (2016). Content analysis of journal articles on Wiki in Science Direct Database. Library Philosophy and Practice (e-journal), 1331, 1-14.

Malhotra, N.K., Mukhopadhyay, S., Liu, X., \& Dash, S. (2012). One, few or Many?: An integrated framework for identifying the items in a measurement scale. International Journal of Marketing Research, 54(6), 835-862. https://doi.org/10.2501/IJMR-54-6-835-862.

McGrath, J. E. (1982). Dilemmatics: The study of research choices and dilemmas. In J.E. McGrath, J. Martin \& R. Kula (Eds.). Judgment calls in research. Beverly Hills, CA: Sage Publications Inc., 69-102.

McNichols, M. F. (2000). Research design issues in earnings management studies. Journal of Accounting and Public Policy, 19, 313-345. 
Mitchell, M. L., \& Jolley, J. M. (2010). Research design explained. Belmont, CA: Wadsworth Cengage Learning, $7^{\text {th }}$ Ed.

Mohajan, H. (2017). Two criteria for good measurements in research: Validity and reliability. Annals of Spiru Haret University, 17(3), 58-82. MPRA Paper No. 83458.

Moller, S. F., von Frese, J., \& Bro, R. (2005). Robust methods of multivariate data analysis. Journal of Chemometrics, 19, 549-563. https://doi.org/10.1002/cem.962.

Morris, E., \& Burkett, K. (2011). Mixed methodologies: A new research paradigm or enhanced quantitative paradigm. Online Journal of Cultural Competence in Nursing and Healthcare, 1(1), 27-36.

Muller, G. (2013). Systems engineering research methods. Procedia Computer Science, 16, 1092-1101. https://doi.org/10.1016./j.procs.2013.01.115.

Nesbary, D. K. (1999). Survey research and the World Wide Web. MA: Allyn \& Bacon.

Onwuegbuzie, A. J., \& Johnson, R. B. (2006). The validity issue in mixed research. Research in the Schools, 13(1), 48-63.

Osuagwu, L. (2008). Business research methodology: Principles \& practice. Lagos: Grey Resources Limited, $4^{\text {th }} \mathrm{Ed}$.

Osuala, E.C. (1990). Introduction to research methodology. Onitsha: African-Fep Publishers Limited, 2nd Ed.

Patton, M. Q. (2012). Qualitative research and evaluation methods. Thousand Oaks, CA: Sage Publications, $3^{\text {rd }}$ Ed.

Pearse, N. (2011). Deciding on the scale granularity of response categories of Likert type scale: The case of a 21-point scale. The Electronic Journal of Business Research Methods, 9(2), 159-171.

Peter, J. P. (1979). Reliability: A review of psychometric basics and recent marketing practices. Journal of Marketing Research, 16, 6-17.

Petersen, A. M., Pan, R. K., Pammolli, F., \& Fortunato, S. (2019). Methods to account for citation inflation in research evaluation. Research Policy, 48, 1855-1865. https://doi.org/10.1016/j.respol.2019.04.009.

Pfeffer, J. (1993). Barriers to the advance of organizational science: Paradigm development as a dependent variable. Academy of Management Review, 18, 599-620.

Pinsonneault, A., \& Kraemer, K. L. (1993). Survey research methodology in management information systems: An assessment. Journal of Management Information Systems, 10(2), 75-105.

Rahi, S. (2017). Research design and methods: A systematic review of research paradigms, sampling issues and instruments development. International Journal of Economics \& Management Sciences, 6(2), 1-5. https://doi.org/10.4172/2162-6359.1000403.

Rajalahti, T., \& Kvalheim, O. M. (2011). Multivariate data analysis in pharmaceuticals: A tutorial review. International Journal of Pharmaceuticals, 417, 280-290. https://doi.org/10.1016/j.ijpharm.2011.02.019

Salazar, M. S. (2015). The dilemma of combining positive and negative items in scales. Psicothema, 27(2), 192-199. (www.psicothema.com).

Sarstedt, M., Bengart, P., Shaltoni, A. M., \& Lehmann, S. (2017). The use of sampling methods in advertising research: A gap between theory and practice. International Journal of Advertising, 1-14. https://doi.org/10.1080/02650487.2017.1348329.

Schmeets, H. (2010). Increasing response rates and the consequences in the Dutch parliamentary election study 2006. Field Methods, 22(4), 391-412. doi: 10.1177/1525822X10381031.

Sharma, S., \& Weathers, D. (2003). Assessing generalizability of scales used in cross-national research. International Journal of Research in Marketing, 20, 287-295. https://doi.org/10.1016/S0167-8116(03)00038-7.

Singh, A. S. (2014). Conducting case study research in non-profit organizations. Qualitative Market Research: An International Journal, 17, 77-84.

Singh, J., \& Modi, N. (2019). Use of information modelling techniques to understand research trends in eye gaze estimation methods: An automated review. Heliyon, 5, 1-12. https://doi.org/10.1016/j.heliyon.2019.e03033.

Stone-Romero, E.F. (2002). The relative validity and usefulness of various empirical research designs. In Rogelberg, S.G. (Ed.), Handbook of Research Methods in Industrial and Organizational Psychology: Blackwell Handbooks of Research Methods in Psychology (pp. 77-98). Malden: Blackwell Publishing, 
Sa, M. J., \& Serpa, S. (2020). Some issues on the funding of the scientific publication in the open access. Academic Journal of Interdisciplinary Studies, 9(4), 77-85.

Scandura, T. A., \& Williams, E. (2000). Research methodology in management: Current practices, Trends, and implications for future research. Academy of Management Journal, 43, 1248-1264.

Schwab-McCoy, A. (2019). The state of statistics education research in client disciplines: Themes and trends across the university. Journal of Statistics Education, 27(3), 253-264. https://doi.org/10.1080/10691898.2019.1687369.

Smallbone, T. \& Quinton, S. (2004). Increasing business students' confidence in questioning validity and reliability of their research. Electronic Journal of Business Research Methods, 2(2), 153-162.

Soutar, G. N., Wilkinson, I., \& Young, L. (2015). Research performance of marketing academics and departments: An international comparison. Australasian Marketing Journal, 23, 155-161. https://doi.org/10.1016/j.ausmj.2015.04.161.

Umer, M., \& Razi, S. (2018). Analyzing research methodologies and publication trends in service marketing literature. Cogent Business \& Management, 5(1), 1-17. https://doi.org/10.1080/2311975.2018.1446265.

Vorobyeva, E., \& Ermakov, P. (2015). Training of psychology students in the scientific methods of research. Procedia-Social and Behavioral sciences, 191, 2699-2703. https://doi.org/10.1016/j.sbspro.2015.04.396.

Wahyuni, D. (2012). The research design maze: Understanding paradigms, cases, methods and methodologies. Journal of Applied Management Accounting Research (JAMAR), 10(1), 69-80.

Walls, J. L., Phan, P. H., \& Berrone, P. (2011). Measuring environmental strategy: Construct development, reliability, and validity. Business \& Society, 50(1), 71-115. https://doi.org/10.1177/0007650310394427.

Williams, C. (2007). Research Methods. Journal of Business \& Economic Research, 5(3), 65-72.

Woodside, A. G. (2013). Moving beyond multiple regression analysis to algorithms: Calling for adoption of a paradigm shift from symmetric to asymmetric thinking in data analysis and crafting theory. Journal of Business Research, 66, 463-472. https://doi.org/10.1016/j.jbusres.2012.12.021.

Yin, R. K. (2003). Case study research design methods. Thousand Oaks, CA: Sage, $3^{\text {rd }}$ Ed.

Yin, R. K. (2012). Applications of case study research. Thousand Oaks, CA: Sage Publications, $3^{\text {rd }}$ Ed.

Zaltman, G. (1997). Rethinking market research: Putting people back in. Journal of Marketing Research, 34(4), 424-437.

\section{Copyrights}

Copyright for this article is retained by the author(s), with first publication rights granted to the journal.

This is an open-access article distributed under the terms and conditions of the Creative Commons Attribution license (http://creativecommons.org/licenses/by/4.0/). 